\title{
ALTERNATIVE STRATEGIES TO CONTROL NEW ZEALAND FLOWER THRIPS ON NECTARINES
}

\author{
G.F. McLAREN and J.A. FRASER
}

The Horticulture and Food Research Institute of New Zealand Ltd., Clyde Research Centre, R.D.1 Alexandra, Central Otago, New Zealand

Corresponding author: gmclaren@hortresearch.co.nz

\begin{abstract}
Experiments conducted in both spring and preharvest (summer) aimed to prevent damage to nectarines caused by New Zealand flower thrips Thrips obscuratus and to minimise quarantine problems caused by thrips on export fruit. Reflective mulch and three insecticide programmes were compared with the standard tau-fluvalinate/chlorpyrifos programme in spring. Abamectin, spinosad and Pyrethrum Plus ${ }^{\circledR}$ reduced spring damage but none was more effective than the existing standard. At harvest time, carbaryl and spinosad plus Nu-film-17 reduced thrips numbers 3 days after treatment, but carbaryl was the only effective insecticide after 5 days. Reflective mulch reduced thrips numbers in spring and preharvest, providing a non-chemical alternative for thrips control. However, supplementary control measures would be needed for this treatment to meet quarantine standards at harvest time. Alternative spring and preharvest programmes for both Integrated Fruit Production and organic systems are suggested for nectarines, but registration is necessary before some insecticides can be used on summerfruit.
\end{abstract}

Keywords: Thrips, nectarines, insecticides, reflective mulch, fruit damage.

\section{INTRODUCTION}

Eleven thrips species have been recorded on blossom and young fruit of nectarines (Prunus persica (L.) Batsch var. nucipersica (Suckow) C.K. Schneid) but adults of New Zealand flower thrips Thrips obscuratus (Crawford) (NZFT) are responsible for the most severe damage (McLaren 1992). NZFT damages nectarines in the spring and infests ripening fruit at harvest time. Spring damage by NZFT can cause fruit to be rejected at harvest, while the presence of thrips on ripe fruit can be responsible for their rejection for export (zero thrips allowed on 600 fruit). Thrips infestations on ripening fruit can cause white stippling and loss of colour on nectarines and peaches.

Control measures are required to prevent thrips infestation for up to 8 weeks in spring (flowering onwards) and just prior to harvest in summer (the month depends on the crop and cultivar). The current spring control programme uses tau-fluvalinate (non-toxic to honeybees) at flowering, and chlorpyrifos between petal and shuck fall. Under Integrated Fruit Production (IFP) these insecticides are applied when thrips numbers exceed monitored thresholds (McLaren \& Fraser 2000) but under conventional systems three to four sprays are applied at 10-day intervals. Currently thrips are controlled prior to harvest, with carbaryl or maldison. Under IFP, alternative treatments are required to replace organophosphate and carbamate pesticides and to reduce the number of applications of synthetic pyrethroid because they are disruptive to predatory mites (McLaren \& Fraser 1993). Organic regimes require the use of non-chemical or BioGroacceptable products.

Several new pesticides and a reflective mulch ground cover were compared with a standard spray programme in five trials conducted between 1996 and 1998 (G.F. McLaren, unpubl. data). The most promising candidates were then compared with the standard 
tau-fluvalinate/ chlorpyrifos programme in 1999-2000. The results of this work are presented in this contribution. In addition, alternatives to carbaryl for the control of thrips before harvest were also investigated.

\section{Spring}

\section{METHODS}

A trial was conducted on a 0.4 ha block of 14 -year old nectarine cv. Fantasia trees growing at $5 \times 2 \mathrm{~m}$ spacing at Clyde Research Centre, Central Otago. Treatments were applied with a handgun to 4-tree plots in a randomised block design with four replicates. Treatments were applied four times: 16 September (80\% bloom), 27 September (petal fall), 7 October and 18 October 1999. Treatments were applied in the morning, with the exception of Pyrethrum Plus ${ }^{\circledR}$, which was applied in the evening. The reflective mulch was installed on 16 September and removed in early November. Details of the treatments are given in Table 1.

TABLE 1: Pesticides applied to nectarine trees for thrips control.

\begin{tabular}{lll}
\hline Treatment & Active ingredient & Product rate/100 litre \\
\hline Pyrethrum Plus $^{\circledR}$ & Mineral oil + pyrethrum & $250 \mathrm{ml}$ \\
Agrimec $^{\circledR}$ & $1.8 \%$ abamectin & $37 \mathrm{ml}$ \\
Success Naturalyte $^{\mathrm{TM}}$ & $12 \%$ spinosad & $40 \mathrm{ml}$ \\
Mavrik $^{\circledR}$ (first application) & $24 \%$ tau-fluvalinate & $20 \mathrm{ml}$ \\
Lorsban $^{\circledR}$ 750WG (3 applications) & $75 \%$ chlorpyrifos & $33.3 \mathrm{~g}$ \\
\hline
\end{tabular}

Thrips were sampled from two trees in each plot twice weekly over seven weeks from flowering to shuck fall ( 29 October). Twenty branches per tree were tapped over a $250 \mathrm{~mm}$ diameter yellow plate and the number of thrips recorded (McLaren \& Fraser 2000). At harvest, 50 fruit were collected from the two central trees in each plot and graded for thrips damage as follows: none (Grade 0), within export standards (Grade 1), within local market standards (Grade 2 ) and reject (Grade 3). Percentage export was estimated by combining Grades 0 and 1 .

\section{Preharvest - trial 1}

On 17 February 1997, lengths of $1.2 \mathrm{~m}$ wide reflective mulch (Extenday ${ }^{\circledR}$ ) were laid on either side of two rows of 10 insecticide-free nectarine cv. Fantasia trees $(4.5 \times 4 \mathrm{~m}$ spacing) at the Clyde Research Centre. Seven days later, at the normal harvest time, 20 fruit were picked from each tree in these two rows and thrips numbers recorded. In addition, 20 fruit/tree were picked from the trees in the two adjacent rows on either side of the mulched rows.

\section{Preharvest - trial 2}

In February 2001, a trial was conducted on insecticide-free nectarine cv. Fantasia trees using a replicated randomised block design with four replicates. Plots consisted of two trees (6 x $4.5 \mathrm{~m}$ spacing) with an untreated tree between each plot. A two-tree space separated this sprayed trial from a block of 28 trees in four rows with reflective mulch laid underneath $\left(1.2 \mathrm{~m}\right.$ wide Extenday $\left.{ }^{\circledR}\right)$. The reflective mulch was installed eight days before the first harvest while the replicated pesticide treatments were applied three days before the first harvest using a handgun.

The following treatments were applied on 16 February 2001:

- $\quad$ Success Naturalyte $40 \mathrm{ml} / 100$ litre

- $\quad$ Success Naturalyte $40 \mathrm{ml} / 100$ litre plus Nu-Film-17 $17^{\mathrm{TM}} 120 \mathrm{ml} / 100$ litre

- Carbaryl 50F (carbaryl) $240 \mathrm{ml} / 100$ litre

Three and five days later (19 and 21 February 2001) 100 fruit per two-tree plot were sampled on each occasion and the number of thrips recorded. 
Thrips/tree, thrips/fruit, and percentage fruit damage data were subjected to analysis of variance by Newman-Keuls test after percentages had been arcsine transformed to stabilise the variance. Data were back-transformed for presentation.

\section{Spring}

\section{RESULTS}

The tau-fluvalinate/chlorpyrifos programme had significantly fewer thrips on the flowers and small fruits, with just 13\% of those found in the untreated population, but thrips numbers on the other four treatments were not significantly different from those of the untreated control trees (Table 2).

Table 2: Mean infestation of nectarine flowers and fruitlets by New Zealand flower thrips on 14 sampling occasions in spring, and damage to fruit at harvest.

\begin{tabular}{lccc}
\hline & $\begin{array}{c}\text { Spring thrips } \\
\text { (thrips/tree) }\end{array}$ & \% with no damage ${ }^{2}$ & $\begin{array}{c}\text { Fruit quality at harvest } \\
\% \text { export }^{2}\end{array}$ \\
\hline Pyrethrum Plus $^{\circledR}$ & $0.84 \mathrm{ab}^{1}$ & $26.9 \mathrm{ab}$ & $68.1 \mathrm{~b}$ \\
Abamectin & $0.73 \mathrm{ab}$ & $33.2 \mathrm{ab}$ & $84.3 \mathrm{a}$ \\
Spinosad & $1.01 \mathrm{ab}$ & $32.1 \mathrm{ab}$ & $71.4 \mathrm{ab}$ \\
Reflective mulch & $1.01 \mathrm{ab}$ & $37.7 \mathrm{ab}$ & $71.4 \mathrm{ab}$ \\
Tau-fluvalinate/ & & $51.2 \mathrm{a}$ & $75.8 \mathrm{ab}$ \\
chlorpyrifos & $0.22 \mathrm{a}$ & $15.0 \mathrm{~b}$ & $54.5 \mathrm{c}$ \\
Untreated & $1.71 \mathrm{~b}$ & & \\
\hline
\end{tabular}

${ }^{1}$ Means followed by the same letter in a column are not significantly different $(\mathrm{P}<0.05)$.

${ }^{2}$ Back-transformed percentages

The tau-fluvalinate/chlorpyrifos programme produced more fruit without damage (Grade 0$)$ than the untreated control trees $(\mathrm{P}<0.05)$, but was not significantly different to the other four treatments. All the treatments produced higher export packouts than from the untreated control trees $(\mathrm{P}<0.05)$. Abamectin, spinosad, reflective mulch and taufluvalinate/chlorpyrifos treatments produced $17-30 \%$ more export grade fruit than the untreated. Pyrethrum Plus ${ }^{\circledR}$ was less effective in terms of \% export fruit than abamectin but not different to the other three treatments.

\section{Preharvest - trial 1}

In 1997, reflective mulch reduced thrips numbers per fruit on the two treated rows compared with the second row on the west side of the mulch, but the mulch had some effect on thrips numbers on the rows nearest to it (Fig. 1). Thrips infestations were reduced from $3 /$ fruit on the outer west row to $0.4 /$ fruit in the mulch rows, an $87 \%$ reduction in thrips numbers.

Preharvest - trial 2

In 2001, trees treated with either spinosad and Nu-Film-17 or carbaryl had lower thrips numbers per fruit than the untreated trees or those treated with spinosad or reflective mulch on day 3 (Fig. 2). Spinosad and reflective mulch reduced thrips numbers compared with the untreated control trees but had more thrips/fruit than the carbaryl or spinosad and Nu-Film-17. However, by day 5, only the carbaryl treatment had significantly lower numbers than all the other treatments. Spinosad (with or without Nu-Film-17) and reflective mulch were still significantly different from the untreated control trees on day 5 but were not as effective as carbaryl. 


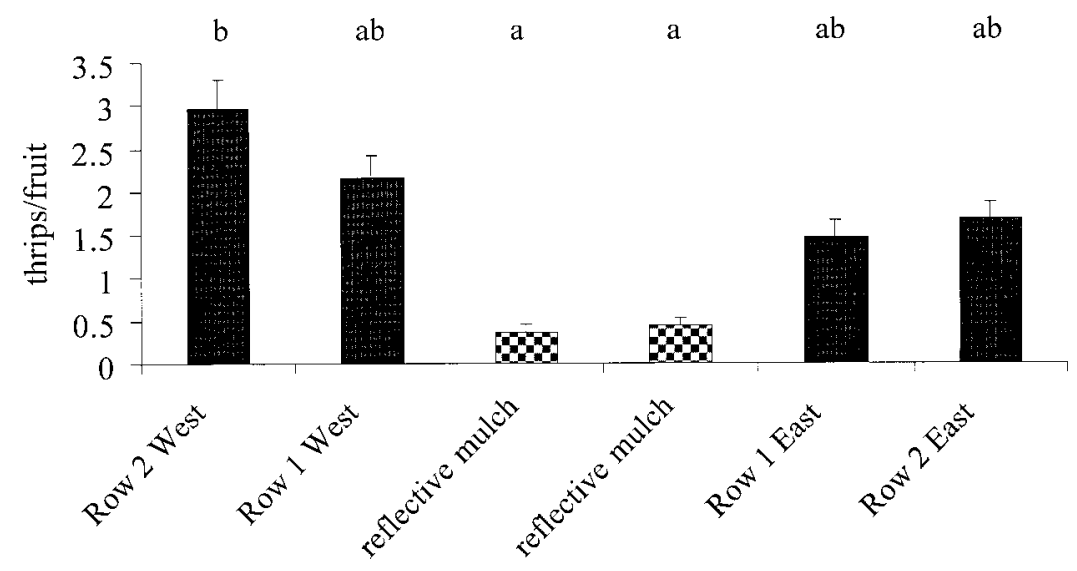

FIGURE 1: Number of New Zealand flower thrips per fruit on two rows of nectarine trees with reflective mulch beneath them compared to trees without mulch on either side of the mulched rows $(n=200$ fruit/row $)$. Bars with the same letter are not significantly different $(P<0.05)$. The SEM is shown for each bar.

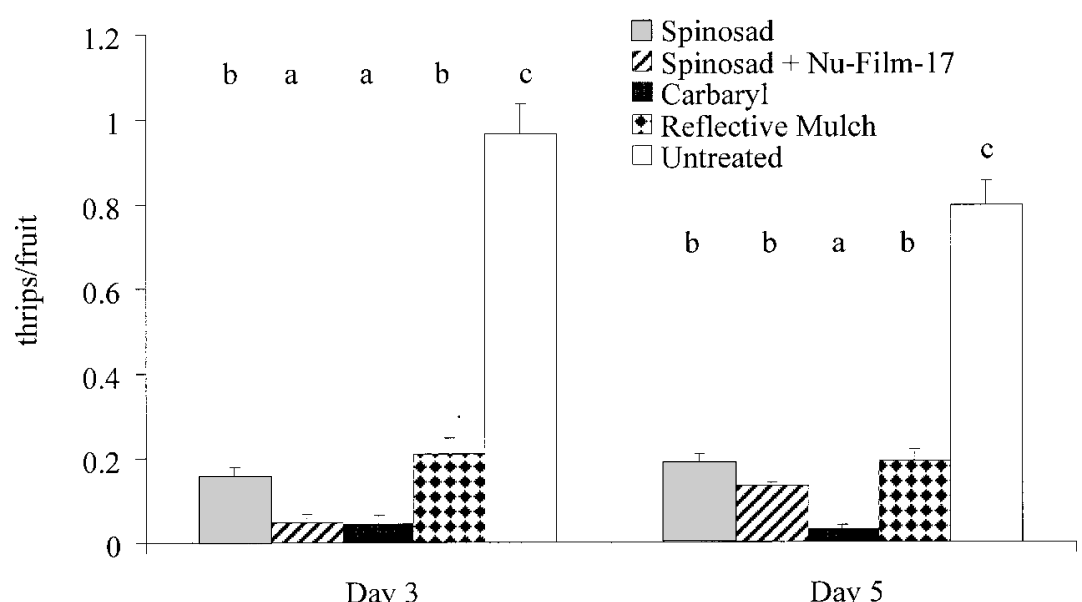

FIGURE 2: Effect of a single application of three treatments and under-tree reflective mulch just before harvest on thrips infestations on nectarine fruit 3 and 5 days after treatment ( $n=400$ fruit/treatment). Bars with the same letter are not significantly different $(\mathbf{P}<0.05)$. The SEM is shown for each bar. 


\section{DISCUSSION AND CONCLUSION}

The existing spring programme of tau-fluvalinate followed by chlorpyrifos was the most effective method of controlling thrips, but alternative insecticides are urgently needed for organic production and for parts of the IFP programme (SummerGreen ${ }^{\mathrm{TM}}$ ) in the near future. Both Pyrethrum Plus ${ }^{\circledR}$ and reflective mulch are accepted in Bio-Gro orchards and are useful options for organic systems. Reflective mulch has not been tested previously for thrips control within New Zealand but it presents a useful nonchemical option, provided the cost-benefit of its use is evaluated over several years. The mode of action of reflective mulch is unclear, but presumably it affects either host orientation by the adult thrips or it disturbs their habitat within the tree.

Two new products, abamectin and spinosad, showed promise for use in conventional and IFP orchards, but neither are currently registered for use on summerfruit. The preharvest trial in 2001 demonstrated how the efficacy of spinosad could be improved by the use of additives such as Nu-Film-17, bringing its performance close to that of the standard carbaryl treatment.

At harvest, carbaryl and spinosad with Nu-Film-17 were equally effective in reducing thrips numbers on fruit three days after treatment, but two days later only carbaryl remained fully effective. Alternative insecticides will be required if, or when, carbaryl is withdrawn from use on export fruit; to this effect spinosad shows promise for preharvest use. Organic growers may use reflective mulch for local market fruit but results presented here suggest that it would not reduce thrips numbers sufficiently to meet quarantine standards for export markets (a full tree canopy is likely to provide some protected sites for thrips). Organic export growers would need to combine reflective mulch with a treatment such as Pyrethrum Plus ${ }^{\circledast}$ to meet the quarantine standard of zero thrips in 600 fruit.

\section{REFERENCES}

McLaren, G.F. 1992: Thrips on nectarines in the spring. Proc. 45th N.Z. Plant Prot. Conf: 111-115.

McLaren, G.F.; Fraser, J.A. 1993: The influence of components of the nectarine spray programme on Typhlodromus occidentalis (Nesbitt). Proc. 46th N.Z. Plant Prot. Conf: 6-10.

McLaren, G.F.; Fraser, J.A. 2000: Development of thresholds for insecticidal control of New Zealand flower thrips on nectarines in spring. N.Z. Plant Prot. 53: 194-199. 